\title{
Cell Differentiation or Development Pathway
}

National Cancer Institute

\section{Source}

National Cancer Institute. Cell Differentiation or Development Pathway. NCI Thesaurus. Code C39704.

A sequence of biological or biochemical events that are involved in embryological or cellular development. 